\title{
Behavioral and quality-of-life outcomes in different service models for methadone maintenance treatment in Vietnam
}

\author{
Bach Xuan Tran ${ }^{1,2^{*}}$, Long Hoang Nguyen ${ }^{1,3}$, Vuong Minh Nong ${ }^{1}$, Cuong Tat Nguyen ${ }^{4}$, Huong Thu Thi Phan ${ }^{5}$
} and Carl A. Latkin ${ }^{2}$

\begin{abstract}
Background: Integrating HIV/AIDS and methadone maintenance treatment (MMT) services with existing health care delivery system is critical in sustaining efforts to fight HIV/AIDS in large injection-driven epidemics. However, efficiency of different integrative service models is unknown. This study assessed behavioral and health-related quality-of-life (HRQOL) outcomes of MMT in four service delivery models and explored factors associated with these outcomes of interest.

Methods: A cross-sectional survey was conducted in two HIV epicenters in Vietnam: Hanoi and Nam Dinh Province. All patients in five selected MMT clinics were invited to participate, and 1016 were interviewed (80-90\% response rate).

Results: Respondents had a mean age of 35.8, taken MMT for average 16.5 months and $3.3 \%$ on MMT for 36-60 months. The MMT integrated with rural district health center (DHC) has the highest prevalence of concurrent drug use (11.3\%). The percentage of condom use (last sexual intercourse) with primary and casual partners was lowest in the MMT at urban DHCs. Patients at the rural DHC reported very high proportions of pain/discomfort (37.8\%), anxiety/depression (43.1 \%), and mobility (13.3\%). In regression models, poorer HRQOL outcomes were found in MMT models in the rural areas or without general health care, and among those patients who were HIV positive, reported concurrent drug use, and had higher numbers of previous drug rehabilitation episodes. Mobility and anxiety/ depression are factors that increased the likelihood of concurrent drug use among MMT patients.
\end{abstract}

Conclusions: Outcomes of MMT were diverse across different integrative service models. Policies on rapid expansion of the MMT program in Vietnam should also emphasize on the integration with comprehensive health care services including psychological supports for patients.

\section{Background}

In Asia, since injecting illicit drugs is recognized as a major risk factor for acquiring HIV, opioid substitution treatments have been considered an important component of HIV/AIDS prevention strategies [1-4]. Methadone maintenance therapy (MMT) has been widely used as a cost-effective intervention for opioid dependence. Evidences demonstrate the positive effects of MMT on people who use drugs (PWUD) by reducing the frequency

\footnotetext{
* Correspondence: bach@hmu.edu.vn

${ }^{1}$ Institute for Preventive Medicine and Public Health, Hanoi Medical University, Hanoi, Vietnam

${ }^{2}$ Johns Hopkins Bloomberg School of Public Health, Baltimore, MD, USA Full list of author information is available at the end of the article
}

of HIV-related behaviors and promoting health care access, health status, and HIV treatment outcomes [5-11]. Methadone has been included in the list of essential medicine for opioid management by the World Health Organization (WHO) in 2004 [12].

Along with HIV/AIDS, opioid illicit drug use was linked to other physical and psychological problems as well as high risk of mortality [6,13-18]. Given the needs of PWUD for comprehensive medical care, the concept of integrating MMT with general health care services was proposed $[9,19-21]$. It refers that various components of health services are provided by single or separate providers in one site. A wide range of literatures suggested the benefits of the integrating MMT to 
general health care facilities in accordance to clinical and public health perspectives. At patient level, this model facilitated health care utilization, improved health outcome, and treatment adherence [22-24]. At facility level, performing integrated services may avoid duplicating services and reduce administrative cost by utilizing fix components of facilities [25-29]. Besides, there are still several barriers that hamper the access and utilization of integrative clinics among drug users, including stigma and discrimination by health workers, acceptability of communities, the lack of comprehensive health care services, and the organization capacity for integration of different services [30-32].

In Vietnam, since the first MMT program was piloted in 2008, 156 MMT clinics have been established and operated with 28,000 DUs enrolling by April 2015 [33, 34]. With its large population of about 200,000 drug users, the Government of Vietnam has a strong political will and action plan to expand MMT services to cover 80,000 drug users by 2015 [7, 33, 35, 36]. Prior studies illustrated the influences of MMT on drug use behaviors, quality of life, and health care expenditure of HIVpositive PWUD $[6,8]$. However, none of them took into account the impact of diverse MMT delivery models. In addition, the rapid cuts in foreign aids require Vietnam to identify strategies to reduce the deficit in resources for MMT as well as other HIV services and programs. Reducing costs, improving efficiency, and mobilizing resources from a wide variety of sources are potential policy options of which evidence on factors associated with the outcomes of service integration is necessary. The current organization of health service delivery system in Vietnam includes four levels: central, provincial, district, and commune [37]. Currently, MMT services are set up as a stand-alone site or integrated with provincial AIDS center (PAC), district health center (DHC), or regional polyclinics (RPC) which is a district-level health facility providing primary and secondary health care services for multiple communes far from the DHC [37]. The purposes of this study were to examine behavioral and health-related quality-of-life (HRQOL) outcomes of MMT in different service delivery models and explore the factors associated with these outcomes of interest.

\section{Methods}

\section{Study settings and sampling}

From January to August 2013, a cross-sectional survey was conducted in two HIV epicenters in Vietnam: Hanoi and Nam Dinh, with 20,717 and 3685 HIV-positive reported cases, respectively. Five clinics were purposively selected in Hanoi and Nam Dinh Provinces. These settings were selected based on some criteria: (1) providing MMT services; (2) covering a wide range of health care levels such as provincial, regional, and district levels; and (3) having adequate patients for the study. These sites were classified into four delivery models:

(1) MMT + HIV voluntary testing and counseling services (VCT) at Nam Dinh PAC;

(2) MMT + rural DHC in Xuan Truong District,

(3) MMT + urban DHC in Tu Liem and Long Bien districts, and

(4)MMT + urban Ha Dong RPC.

Both rural and urban DHCs in this study provide MMT along with antiretroviral treatment (ART) and general health care. Meanwhile, the Ha Dong RPC only provides general health care. During the period of this study, those services were co-located in one site with different health workers. Eligible subjects were 18 years or above, participating or having demand to enroll into the program. Patients meeting the criteria and presenting at the clinic during the whole study period were invited; and if they agreed to participate, an informed consent was given to them for signature. A total of 1016 respondents were recruited in the study. Since patients in our sample were receiving MMT free-of-charge, they did not receive any extra incentive for answering the survey. The response rate was $80-90 \%$ across different sites (Table 1).

\section{Measures and instruments}

Socioeconomic status, high-risk behaviors, and HRQOL of respondents were collected by face-to-face interview using structured questionnaires. Behaviors of interest include current drug use and condom use (last sexual intercourse) with intimate, casual, and commercial sex partners that were self-reported by respondents. HRQOL was measured by using EuroQol - five dimensions - five levels (EQ-5D-5L) instrument. The descriptive system includes five domains: mobility, self-care, usual activities, pain/discomfort, and anxiety/depression with five levels of response: no problems, slight problems, moderate problems, severe problems, and extreme problems, giving 3125 health states with respective single indexes. To compute those indexes, the EQ-5D-5L value set of Thailand was used in the absence of such values for Vietnam [38]. Additionally, the EuroQol - Visual Analog Scale (EQ-VAS) assesses the self-rated health of respondents in a scale from 0 to 100 points, labeled "the best health you can imagine" and "the worst health you can imagine." The Vietnamese version of EQ-5D-5L was translated and has been widely applied in HIV and drug use populations of Vietnam [8, 15, 33, 38-40]. EQ5D-5L and EQ-VAS have been shown to perform good measurement properties and be responsive in monitoring 
Table 1 Characteristics of study sites

\begin{tabular}{lllll}
\hline Level & Settings & Site name & Type of services & Sample size \\
\hline Province & Nam Dinh City & Provincial AIDS center & MMT + VCT & 270 \\
District (rural) & Xuan Truong District & District health center & MMT + VCT + ART + GH & 151 \\
District (urban) & Tu Liem District & District health center & MMT + VCT + ART + GH & 201 \\
District (urban) & Long Bien District & District health center & MMT + VCT + ART + GH & 184 \\
District (urban) & Ha Dong District & Regional polyclinic & MMT + GH & 210 \\
\hline
\end{tabular}

the health status of HIV-affected patients groups in Vietnam $[5,15,33,38-40]$.

\section{Statistical analysis}

ANOVA and chi-squared test were used to assess the difference of characteristics and behavioral and HRQOL outcomes between different MMT models. Multivariate linear regression and logistic regression were performed to determine the factors related to outcomes of interest. Predictors of outcomes included sociodemographic characteristics, history of drug use and rehabilitation, health status and HIV infection, current drug-related behaviors, and service delivery models. Backward stepwise selection strategy was used to reduce the models, with variables having $p$ values of log-likelihood ratio test $<0.1$ included. Statistical significance was set at $p$ value $<0.05$.

\section{Ethical approval}

The research was approved by the Scientific Committee of the Authority of HIV/AIDS Control, Ministry of Health, Vietnam.

\section{Results}

A total of 1016 patients enrolled into the study, 997 taking MMT daily for average 16.5 months; 19 other patients were not included in this analysis since they had registered but not yet taken methadone. There were $19.7 \%$ of the patients taking MMT for over 24 months; and $3.3 \%$ were treated for 36-60 months. The mean age of patients was $36.7(\mathrm{SD}=7.6)$ years. Among those, only $1.28 \%$ were female, $67.7 \%$ lived with spouse or partners. The majority had less than high school education (55.3\%) and cult of ancestors (or ancestral veneration) (88.2\%). The percentage of participants reporting HIVpositive status was $8.1 \%$. Compared to other sites, the rural MMT clinics integrated with Xuan Truong DHC have a large proportion of patients who were Catholic $(25.8 \%)$ and who were manual workers or farmers (35.8\%) (Table 2).

In Table 3, history of drug use and previous drug use rehabilitation are compared among patients of four service models. On average, patients used drug for the first time at the age of 24.1 (SD =6.5), for 13.5 years, and had about five episodes of drug rehabilitation prior to the MMT. Patients at the rural MMT clinic started using drugs at earlier ages and experienced fewer times of drug rehabilitation than patients at other clinics. The location of rehabilitation included self-management at home (71.6\%), voluntary centers (47.8\%), and compulsory centers $(27.2 \%)$. As for the reason for relapse, craving and peer inducement were the two major causes as reported by half of the patients.

Table 4 presents the current drug use, condom use, and self-reported HRQOL of patients participating in each MMT model. We found heterogeneity in these outcomes across different service models, but it was largely contributed by geographical location. There were less than $5 \%$ of the patients who reported current drug use during MMT; however, it was the highest in the rural MMT integrated with Xuan Truong DHC (13.1\%). Among sexually active individuals, most services also, the percentage of patients using condom (last sexual intercourse) with their primary and casual partners was lowest in urban MMT at DHC in comparison with other clinics. Overall, $95.4 \%$ of the patients reported that their HRQOL had improved to some extent over MMT. The proportion of patients who reported having any health problem across five dimensions of the EQ-5D instrument in the rural areas was double than that of all patients in the sample. Patients who were attending the urban MMT integrated with Ha Dong RPC reported smallest proportions of all health problems among selected sites.

Table 5 explored the related factors with current drug use and HRQOL of MMT patients in the reduced linear regression models. These models specified the association between service models and duration of MMT with the outcomes of interest while adjusting for other covariates. Although no significant difference in current drug use between service models was found, MMT clinics integrated with urban DHC and RPC showed better HRQOL outcome measured using VAS, and the rural MMT showed the lowest EQ-5D index score. Duration on MMT is also associated with reduced likelihood of current drug use among those retained on MMT, while having any problems in mobility $(\mathrm{OR}=4.2)$ and anxiety/ depression ( $\mathrm{OR}=3.1)$ during MMT substantially increased the risk of current drug use.

There are several sociodemographic factors and history of drug use associated with HRQOL outcomes of MMT. 
Table 2 Sociodemographic characteristics of respondents

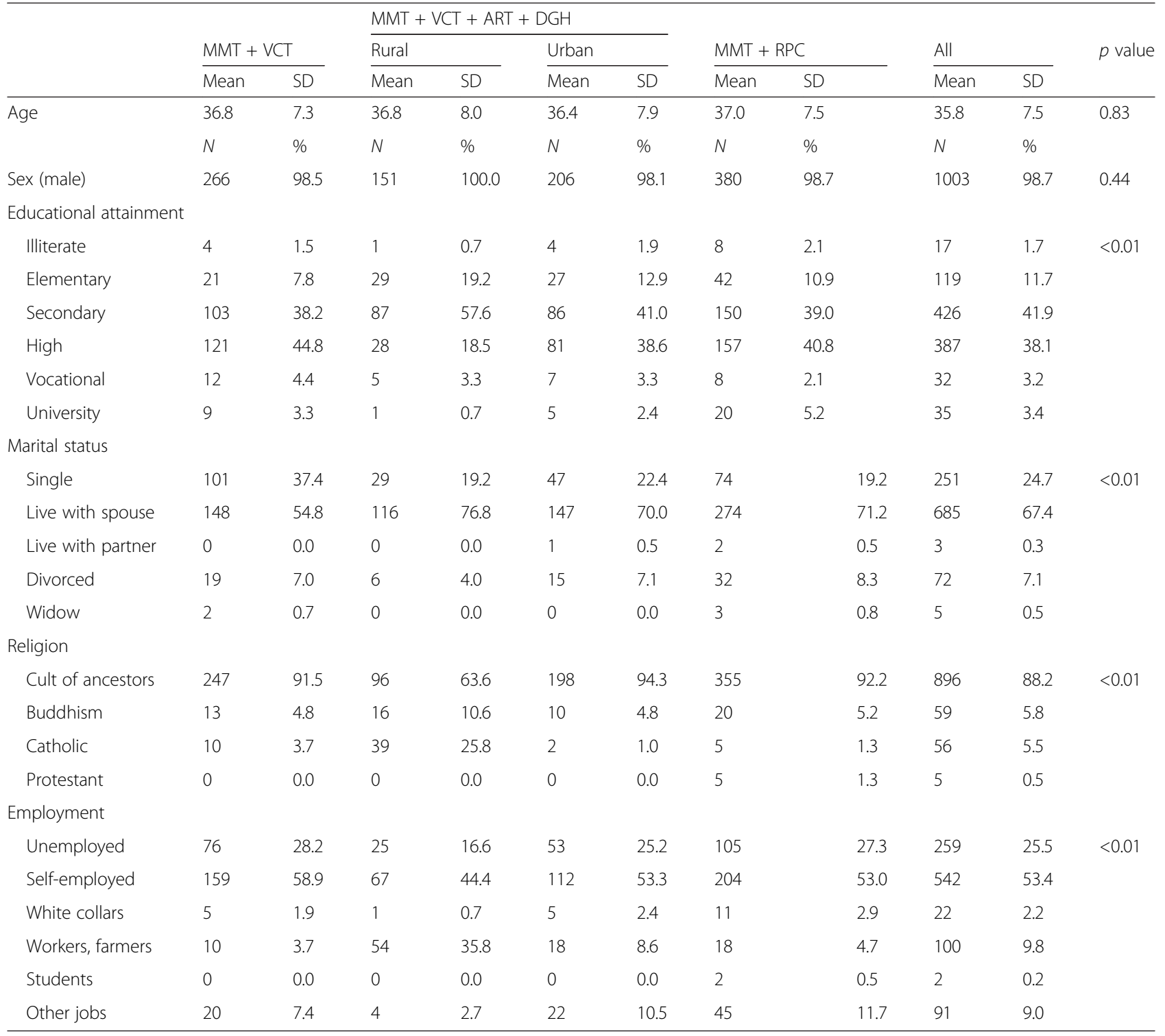

Unemployment, HIV-positive status, concurrent drug use, and higher numbers of previous drug rehabilitation episodes were associated with decreased HRQOL among MMT patients.

\section{Discussion}

While integration and decentralization of HIV/AIDS and substance abuse treatment services with existing health care delivery system is critical in sustaining efforts to fight HIV/AIDS in large injection-driven epidemics, findings of this study showed a significant heterogeneity in outcomes of MMT across different service models. However, variability in MMT outcomes was largely contributed by the geographical differences. Although previous studies determined that long-term MMT in general will bring about improvements in health status and reduce the likelihood of concurrent drug use among patients [41]; we found poorer HRQOL outcomes in rural or lower level MMT clinics. If the goal is to engage drug users with MMT in a timely manner and prevent HIV transmission, it is necessary that not only HIV-related interventions but also general health care should be provided $[13,35,36,42]$. These findings support current policies on scaling up MMT program in Vietnam and inform the development of more comprehensive care and support services for drug users as well as building capacity of health workers in substance abuse treatment in large drug-using populations.

This is the first study profiling the outcomes of different integrative models for delivering MMT. It contributes to the literature empirical evidence that the integration of MMT with existing health care services 
Table 3 History of drug use and rehabilitation

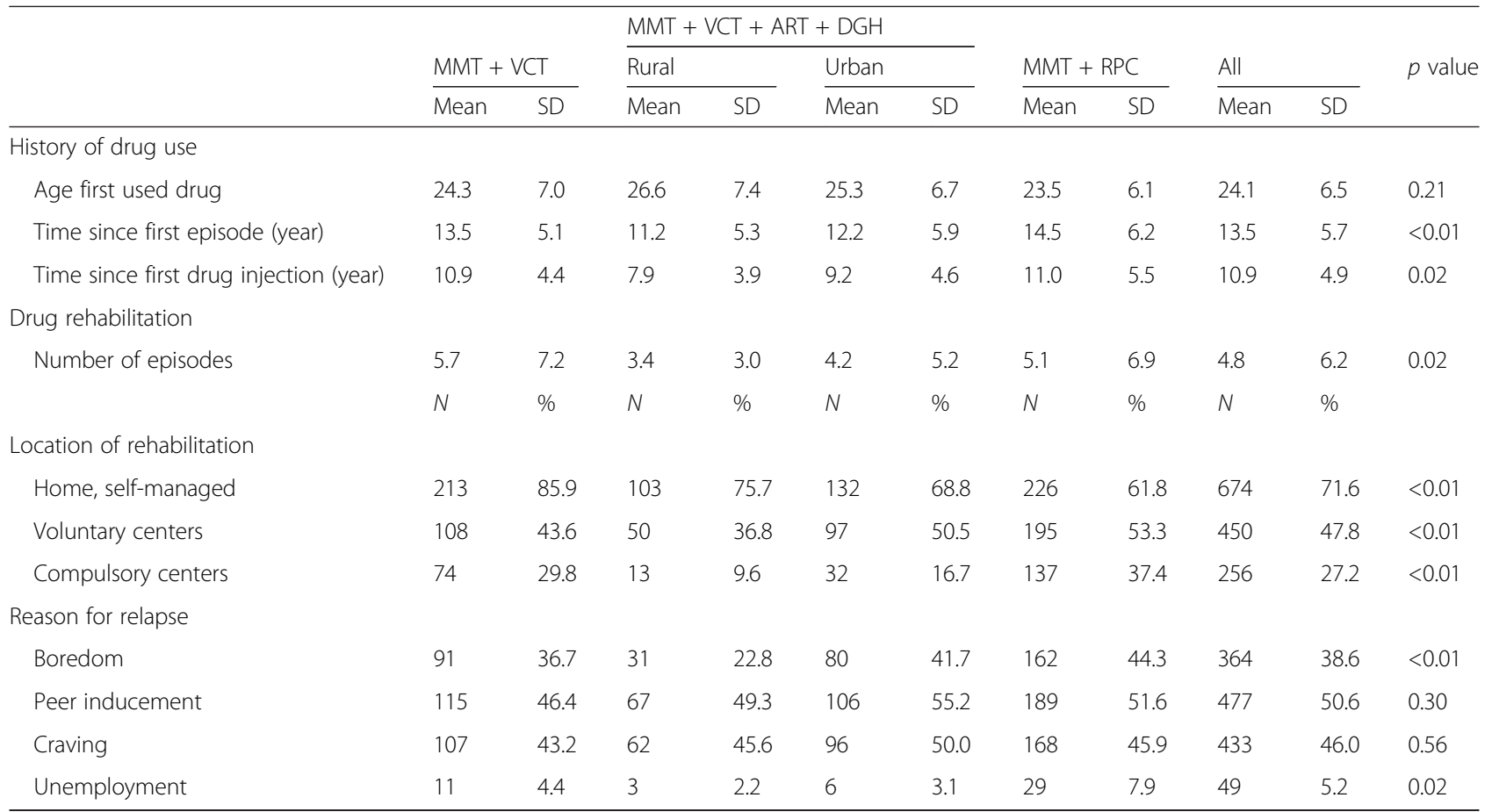

will yield better outcomes [36, 43]. In literatures, integration has potential roles to facilitate the continuity of care and increased access to medical services [19, 44-46]. Besides, patients participating in this model have lower costs for health care due to fewer admissions to hospitals, reducing their health care expenditure and household economic burden $[8,33,47]$. Those reasons may results in better health outcomes of patients in integrated clinics at PRC and urban DHC compared to other clinics.

This study reaffirms the reduced drug use behaviors over the course of MMT that support previous study on the cost-effectiveness of short-term MMT for drug users

Table 4 Behavioral and quality-of-life outcomes by different service models

\begin{tabular}{|c|c|c|c|c|c|c|c|c|c|c|c|}
\hline & \multirow{2}{*}{\multicolumn{2}{|c|}{$\mathrm{MMT}+\mathrm{VCT}$}} & \multicolumn{4}{|c|}{$\mathrm{MMT}+\mathrm{VCT}+\mathrm{ART}+\mathrm{DGH}$} & \multirow{2}{*}{\multicolumn{2}{|c|}{$\mathrm{MMT}+\mathrm{RPC}$}} & \multirow{2}{*}{\multicolumn{2}{|c|}{ All }} & \multirow{3}{*}{$p$ value } \\
\hline & & & \multicolumn{2}{|l|}{ Rural } & \multicolumn{2}{|l|}{ Urban } & & & & & \\
\hline & N & $\%$ & N & $\%$ & N & $\%$ & N & $\%$ & $N$ & $\%$ & \\
\hline Concurrent drug use & 15 & 5.6 & 17 & 11.3 & 11 & 5.2 & 6 & 1.6 & 49 & 4.8 & $<0.01$ \\
\hline \multicolumn{12}{|c|}{ Condom use (last sexual intercourse) } \\
\hline Intimate partners & 58 & 30.4 & 40 & 30.5 & 30 & 17.4 & 97 & 31.7 & 225 & 28.1 & 0.01 \\
\hline Casual partners & 6 & 75.0 & 11 & 64.7 & 4 & 30.8 & 14 & 60.9 & 35 & 57.4 & 0.15 \\
\hline Commercial sex partners & 16 & 94.1 & 16 & 88.9 & 11 & 91.7 & 28 & 77.8 & 71 & 85.5 & 0.35 \\
\hline Improved QOL & 255 & 94.8 & 132 & 97.1 & 205 & 97.6 & 360 & 94.0 & 952 & 95.4 & 0.18 \\
\hline \multicolumn{12}{|l|}{ Reported health problems } \\
\hline Mobility & 19 & 7.0 & 20 & 13.3 & 15 & 7.1 & 20 & 5.2 & 74 & 7.3 & 0.02 \\
\hline Self-care & 10 & 3.7 & 9 & 6.0 & 9 & 4.3 & 12 & 3.1 & 40 & 3.9 & 0.49 \\
\hline Usual activities & 18 & 6.7 & 17 & 11.3 & 9 & 4.3 & 16 & 4.2 & 60 & 5.9 & 0.01 \\
\hline Pain or discomfort & 37 & 13.7 & 57 & 37.8 & 34 & 16.2 & 52 & 13.5 & 180 & 17.7 & $<0.01$ \\
\hline \multirow[t]{2}{*}{ Anxiety or depression } & 56 & 20.7 & 65 & 43.1 & 38 & 18.1 & 51 & 13.3 & 210 & 20.7 & $<0.01$ \\
\hline & Mean & SD & Mean & SD & Mean & SD & Mean & SD & Mean & SD & Mean \\
\hline \multicolumn{12}{|l|}{ Health utility } \\
\hline EQ-5D single index & 91.2 & 15.1 & 82.7 & 16.5 & 91.4 & 15.3 & 93.3 & 13.4 & 83.4 & 20.5 & $<0.01$ \\
\hline VAS & 76.4 & 15.3 & 75.8 & 16.2 & 78.8 & 14.3 & 78.3 & 13.0 & 74.8 & 16.8 & 0.09 \\
\hline
\end{tabular}


Table 5 Factors associated with concurrent drug use and quality-of-life outcomes of MMT

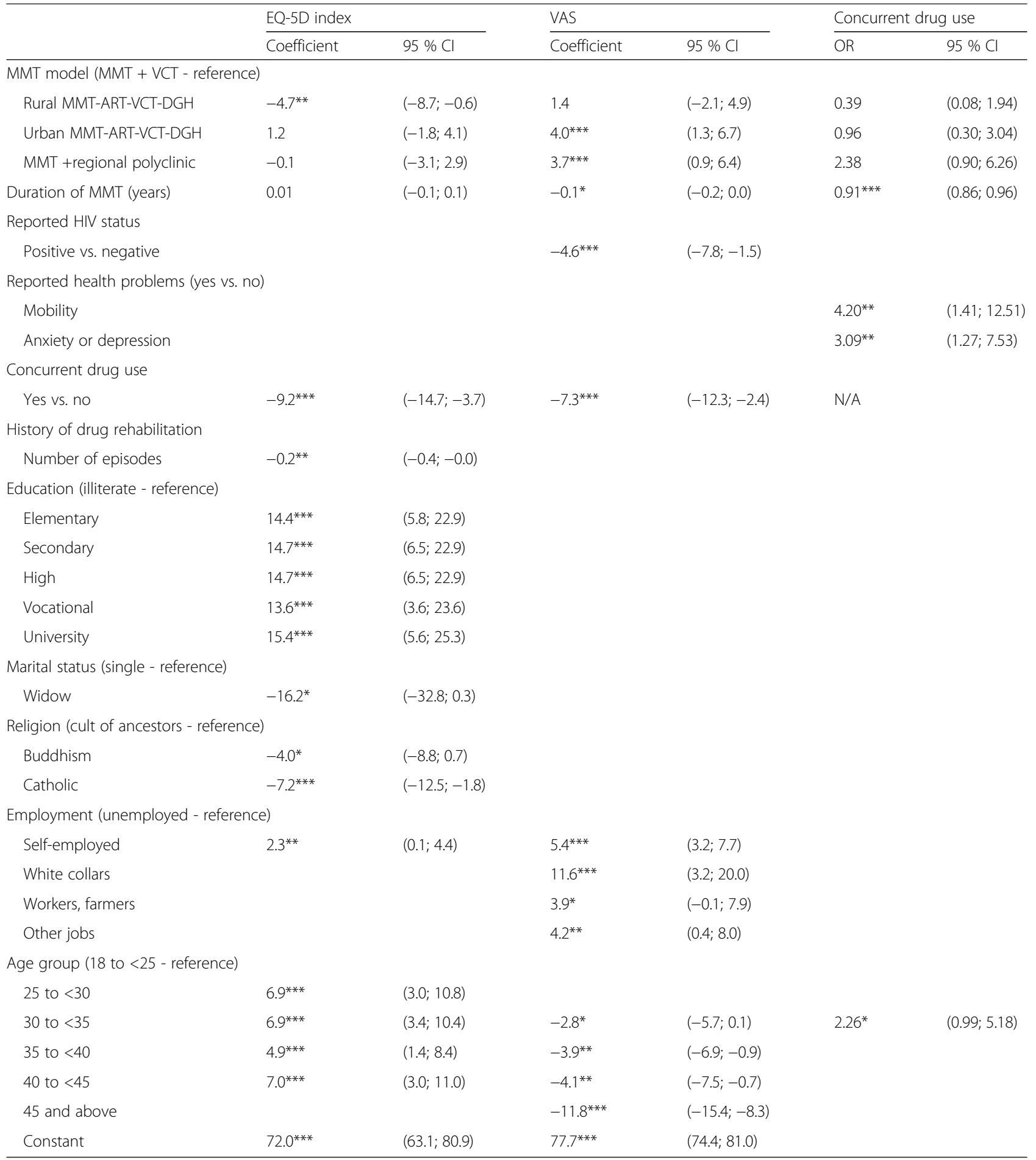

$\mathrm{Cl}$ in parentheses

${ }^{* * *} p<0.01 ;{ }^{* *} p<0.05 ;{ }^{*} p<0.1$

regardless of their HIV status [5, 7]. The overall HRQOL score measured using EQ-5D in this study was higher than HIV-positive drug users taking MMT and lower than the general population in Vietnam $[6,8,14,15,38,39]$. However, patients attending rural or decentralized services had clinically important differences in HRQOL compared to others. We observed a very high proportion of having problems in pain/discomfort and anxiety/depression and notably in mobility among patients attending MMT at the rural DHC. The proportion of having any problem in 
mobility of the general population and HIV-positive group was 2.1 and $7.5 \%$, respectively [15]. In measuring healthrelated quality of life, VAS is a valid measure that captures the values of patients attached to their current health states which is no different than the gold standard method for measuring preference-based HRQOL-the Standard Gamble [39]. VAS score had not increased over long-term MMT that could be explained by the fact that drug users receiving MMT still have many other social, economic, and health concerns $[6,13,14,38,48]$. As observed in previous studies in Vietnam, we found that HIV status, current drug use, history of drug rehabilitation, duration of drug use prior to MMT, and various socioeconomic characteristics of respondents were significantly associated with HRQOL outcomes [6, 8, 13-15, 38, 48-50].

Integration has been raised as a priority in the context of limited resources for HIV/AIDS responses [35, 36, 51]. In economic theory, this model has the potential advantages on technical (focusing on unit cost of services) and allocative efficiency (focusing on cost-effectiveness of services) [52]. Recent studies confirmed that integrated HIV/ AIDS service delivery was more efficient than stand-alone services $[9,20]$. However, none of them mentioned the efficiency of integrated MMT services with general/primary health care. Findings of this study have implications to inform the expansion and management of MMT services in Vietnam. First, the majority of patients registering at new MMT sites might be younger and have more physical and mental health problems. Depression and other mental disorders have been known as a predictor of drug relapse and HIV risk behaviors and negatively affect antiretroviral treatment outcomes [53-55]. Therefore, integrating MMT clinics with general health care facilities is necessary, and general health care and psychological support should be provided to drug users prior to and during MMT. Second, in the rural areas, the long distance to MMT clinics can be a barrier to the access and adherence of patients. It is important to notice that in this analysis, $13.3 \%$ of the patients have problems in mobility, and this group is about four times more likely to use drugs concurrently than their counterpart. Since patients require daily uptake of the medication, a satellite model that links the MMT at DHC with commune health stations for delivering MMT in large drug-using populations could be highly efficient. Besides, take-home dose may also be an option that helps overcome the geographical barriers and improve adherence of patients. However, with the current policies, the management and delivery of methadone medication that does not support the implementation of take-home dose in short term is restricted.

The strength of this study was the participation of a large sample size in various levels of the health care system. In addition, validated instruments (EQ-5D-5L and VAS) were employed to allow for the comparability of measurements. However, the study has limitations. First, the cross-sectional design may not allow the causal relations between MMT delivery models and the changes of HRQOL as well as risk behaviors of respondents. Second, the collected data was based on self-reported information, which was subject to desirability bias due to respondents' recall. In this study, concurrent drug use was self-reported that might underestimate the actual prevalence among MMT patients. In addition, we only interviewed the patients who remained at the MMT clinics while missing those who dropped out of the program. In addition, we did not have information regarding MMT doses and patient responses. Finally, the generalization of study was limited due to convenience sampling technique.

\section{Conclusions}

In conclusion, the study supports the effectiveness of MMT for drug users in Vietnam and preferable outcomes of integrating MMT with existing health services. Heterogeneities in behavioral and HRQOL outcomes across different integrative MMT service models suggest a need not only to provide HIV-related interventions but also the value of comprehensive health care including psychological supports for MMT patients especially in rural areas. Future research should examine the costs and efficiency of satellite models for dispensing MMT where distance to the clinic is a barrier to service access and utilization.

\section{Competing interest \\ The authors declare that they have no competing interests}

\section{Authors' contributions}

BXT, HTTP, CL, LHN, VMN, and CTN conceived of the study, participated in its design and implementation, and wrote the manuscript. LHN, VMN, and CTN analyzed the data. BXT, LHN, HTTP, CL, and CTN helped to draft the manuscript. All authors read and approved the final manuscript.

\section{Acknowledgements}

The authors would like to acknowledge supports by the Vietnam Authority of HIV/AIDS Control for the use of this survey data. There was no funding for this analysis.

Ethics approval and consent to participate

Written informed consent was provided by the participants after being clearly explained about the study.

\section{Consent for publication}

All authors read the manuscript and have consent to publish it.

\section{Author details}

${ }^{1}$ Institute for Preventive Medicine and Public Health, Hanoi Medical University, Hanoi, Vietnam. ${ }^{2}$ Johns Hopkins Bloomberg School of Public Health, Baltimore, MD, USA. ${ }^{3}$ School of Medicine and Pharmacy, Vietnam National University, Hanoi, Vietnam. ${ }^{4}$ Institute for Global Health Innovations, Duy Tan University, Da Nang, Vietnam. ${ }^{5}$ Authority of HIV/AIDS Control, Ministry of Health, Hanoi, Vietnam.

Received: 18 October 2015 Accepted: 14 January 2016

Published online: 02 February 2016 


\section{References}

1. The Commission on AIDS in Asia. Redefining AIDS in Asia: Crafting an effective response. Oxford University Press; 2008; 258. Available at http://www.unaids. org/en/media/unaids/contentassets/dataimport/pub/report/2008/20080326_ report_commission_aids_en.pdf. Accessed November 1, 2012.

2. Wu Z, Shi CX, Detels R. Addressing injecting drug use in Asia and Eastern Europe. Curr HIV/AIDS Rep. 2013;10:187-93.

3. Wolfe D. Paradoxes in antiretroviral treatment for injecting drug users: access, adherence and structural barriers in Asia and the former Soviet Union. Int J Drug Policy. 2007;18:246-54.

4. Wodak A. The challenge of HIV spread among and from injecting drug users in Asia. Dev Bull. 2000;42-4.

5. Tran BX, Ohinmaa A, Duong AT, Do NT, Nguyen LT, et al. Cost-effectiveness of methadone maintenance treatment for HIV-positive drug users in Vietnam. AIDS Care. 2012:24:283-90.

6. Tran BX, Ohinmaa A, Duong AT, et al. Changes in drug use are associated with health-related quality of life improvements among methadone maintenance patients with HIV/AIDS. Qual Life Res. 2012;21:613-23.

7. Tran BX, Ohinmaa A, Duong AT, Nguyen LT, Vu PX, Mills S, et al. The costeffectiveness and budget impact of Vietnam's methadone maintenance treatment programme in HIV prevention and treatment among injection drug users. Glob Public Health. 2012;7:1080-94.

8. Tran BX, Nguyen LT. Impact of methadone maintenance on health utility, health care utilization and expenditure in drug users with HIV/AIDS. Int J Drug Policy. 2013;24:e105-10.

9. Gourevitch MN, Chatterji P, Deb N, Schoenbaum EE, Turner BJ. On-site medical care in methadone maintenance: associations with health care use and expenditures. J Subst Abuse Treat. 2007;32:143-51.

10. Connock M, Juarez-Garcia A, Jowett S, Frew E, Liu Z, Taylor RJ, et al. Methadone and buprenorphine for the management of opioid dependence: a systematic review and economic evaluation. Health Technol Assess. 2007:11(1-171):iii-iv.

11. Reid G, Sharma M, Higgs P. The long winding road of opioid substitution therapy implementation in South-East Asia: challenges to scale up. J Public Health Res. 2014;3:204.

12. World Health Organization. Proposal for the inclusion of Methadone in the WHO model list of essential medicines. Geneva, Switzerland: 2004.

13. Tran BX, Ohinmaa A, Mills S, Duong AT, Nguyen LT, Jacobs $P$, et al. Multileve predictors of concurrent opioid use during methadone maintenance treatment among drug users with HIV/AIDS. PLoS One. 2012;7:e51569.

14. Tran BX. Quality of life outcomes of antiretroviral treatment for HIV/AIDS patients in Vietnam. PLoS One. 2012;7:e41062

15. Tran BX, Ohinmaa A, Nguyen LT, Nguyen TA, Nguyen TH. Determinants of health-related quality of life in adults living with HIV in Vietnam. AIDS Care. 2011:23:1236-45.

16. Gupta S, Granich R, Suthar AB, Smyth C, Baggaley R, Sculier D, et al. Global policy review of antiretroviral therapy eligibility criteria for treatment and prevention of HIV and tuberculosis in adults, pregnant women, and serodiscordant couples. J Acquir Immune Defic Syndr. 2013:62:e87-97.

17. Iskandar S, Kamal R, De Jong CA. Psychiatric comorbidity in injecting drug users in Asia and Africa. Curr Opin Psychiatry. 2012;25:213-8.

18. Wolfe D, Carrieri MP, Shepard D. Treatment and care for injecting drug users with HIV infection: a review of barriers and ways forward. Lancet. 2010;376:355-66.

19. Bruce RD, Lambdin B, Chang O, Masao F, Mbwambo J, Mteza I, et al. Lessons from Tanzania on the integration of HIV and tuberculosis treatments into methadone assisted treatment. Int J Drug Policy. 2014;25:22-5.

20. Tran BX, Ohinmaa A, Duong AT, Nguyen LT, Vu PX, Mills S, et al. Costeffectiveness of integrating methadone maintenance and antiretroviral treatment for HIV-positive drug users in Vietnam's injection-driven HIV epidemics. Drug Alcohol Depend. 2012;125:260-6.

21. Sheridan J, Goodyear-Smith F, Butler R, Wheeler A, Gohns A. Barriers to, and incentives for, the transfer of opioid-dependent people on methadone maintenance treatment from secondary care to primary health care. Drug Alcohol Rev. 2008:27:178-84.

22. Wang L, Wei X, Wang X, Li J, Li H, Jia W. Long-term effects of methadone maintenance treatment with different psychosocial intervention models. PLoS One. 2014;9:e87931

23. Reddon H, Milloy MJ, Simo A, Montaner J, Wood E, Kerr T, et al. Methadone maintenance therapy decreases the rate of antiretroviral therapy discontinuation among HIV-positive illicit drug users. AIDS Behav. 2014;18:740-6.
24. Peles E, Schreiber S, Adelson M. Trends in substance abuse and infectious disease over 20 years in a large methadone maintenance treatment (MMT) clinic in Israel. Subst Abus. 2014.

25. Masson $\mathrm{CL}$, Barnett $\mathrm{PG}$, Sees $\mathrm{KL}$, Delucchi $\mathrm{KL}$, Rosen $\mathrm{A}$, Wong W, et al. Cost and cost-effectiveness of standard methadone maintenance treatment compared to enriched 180-day methadone detoxification. Addiction. 2004;99:718-26

26. Dijkgraaf MG, van der Zanden BP, de Borgie CA, Blanken $P$, van Ree JM, van den Brink W, et al. Cost utility analysis of co-prescribed heroin compared with methadone maintenance treatment in heroin addicts in two randomised trials. BMJ. 2005:330:1297.

27. Vanagas G, Padaiga Z, Bagdonas E. Cost-utility analysis of methadone maintenance treatment: a methodological approach. Subst Use Misuse. 2006;41:87-101.

28. Afriandi I, Siregar AY, Meheus F, Hidayat T, van der Ven A, van Crevel R, et al. Costs of hospital-based methadone maintenance treatment in HIV/AIDS control among injecting drug users in Indonesia. Health Policy. 2010;95:69-73.

29. Tran BX, Ohinmaa A, Duong AT, Nguyen LT, Vu PX, Mills S, et al. The costeffectiveness and budget impact of Vietnam's methadone maintenance treatment programme in HIV prevention and treatment among injection drug users. Glob Public Health. 2012;7:1080-94.

30. Lambdin BH, Mbwambo JK, Josiah RM, Bruce RD. Service integration: opportunities to expand access to antiretroviral therapy for people who inject drugs in Tanzania. J Int AIDS Soc. 2015;18:19936.

31. Kinahan JC, Surah S, Keating S, Bergin C, Mulcahy F, Lyons F, et al. Effect of integrating HIV and addiction care for non-engaging HIV-infected opiate-dependent patients. Ir J Med Sci. 2015.

32. Guerrero EG, Aarons GA, Palinkas LA. Organizational capacity for service integration in community-based addiction health services. Am J Public Health. 2014;104:e40-7.

33. Tran BX. Willingness to pay for methadone maintenance treatment in Vietnamese epicentres of injection-drug-driven HIV infection. Bull World Health Organ. 2013;91:475-82.

34. Nguyen TT, Nguyen LT, Pham MD, Vu HH, Mulvey KP. Methadone maintenance therapy in Vietnam: an overview and scaling-up plan. Adv Prev Med. 2012;2012:732484

35. Tran BX, Nguyen LH, Phan HT, Nguyen LK, Latkin CA. Preference of methadone maintenance patients for the integrative and decentralized service delivery models in Vietnam. Harm Reduct J. 2015;12:29.

36. Tran BX, Nguyen LH, Phan HT, Latkin CA. Patient satisfaction with methadone maintenance treatment in vietnam: a comparison of different integrative-service delivery models. PLoS One. 2015;10:e0142644.

37. Tran BX, Van Hoang M, Nguyen HD. Factors associated with job satisfaction among commune health workers: implications for human resource policies. Glob Health Action. 2013:6:1-6.

38. Tran BX, Ohinmaa A, Nguyen LT. Quality of life profile and psychometric properties of the EQ-5D-5L in HIV/AIDS patients. Health Qual Life Outcomes. 2012;10:132

39. Tran B, Nguyen L, Ohinmaa A, Maher R, Nong V, Latkin CA. et al. Longitudinal and cross sectional assessments of health utility in adults with HIV/AIDS: a systematic review and meta-analysis. BMC Health Serv Res. 2015;15:7.

40. Tran BX, Nong VM, Maher RM, Nguyen PK, Luu HN. A systematic review of scope and quality of health economic evaluation studies in Vietnam. PLoS One. 2014;9:e103825.

41. George S. Review: methadone increases retention and reduces heroin use compared with non-pharmacological maintenance. Evid Based Ment Health. 2010;13:26

42. Nguyen NT, Tran BX, Hwang LY, Markham CM, Swartz MD, Vidrine Jl, et al, Motivation to quit smoking among HIV-positive smokers in Vietnam. BMC Public Health. 2015;15:326.

43. Tran BX, Nguyen LH, Phan HT, Nguyen LK, Latkin CA. Preference of methadone maintenance patients for the integrative and decentralized service delivery models in Vietnam. Harm Reduct J. 2015:12:29.

44. Harris Jr KA, Arnsten JH, Litwin AH. Successful integration of hepatitis C evaluation and treatment services with methadone maintenance. J Addict Med. 2010;4:20-6.

45. Palepu A, Tyndall MW, Joy R, Kerr T, Wood E, Press N, et al. Antiretroviral adherence and HIV treatment outcomes among HIV/HCV co-infected injection drug users: the role of methadone maintenance therapy. Drug Alcohol Depend. 2006;84:188-94. 
46. Herman M, Gourevitch MN. Integrating primary care and methadone maintenance treatment: implementation issues. J Addict Dis. 1997;16:91-102.

47. Tran BX, Duong AT, Nguyen LT, Hwang J, Nguyen BT, Nguyen QT, et al. Financial burden of health care for HIV/AIDS patients in Vietnam. Trop Med Int Health. 2013;18:212-8.

48. Tran BX, Nguyen NP. Patient satisfaction with HIV/AIDS care and treatment in the decentralization of services delivery in Vietnam. PLoS One. 2012;7:e46680.

49. Tran BX, Nguyen LT, Nguyen NH, Hoang QV, Hwang J. Determinants of antiretroviral treatment adherence among HIV/AIDS patients: a multisite study. Glob Health Action. 2013;6:19570.

50. Tran BX, Ohinmaa A, Nguyen LT, Oosterhoff P, Vu PX, Vu TV, et al. Gender differences in quality of life outcomes of HIV/AIDS treatment in the latent feminization of HIV epidemics in Vietnam. AIDS Care. 2012;24:1187-96.

51. Nguyen $L H$, Tran $B X$, Nguyen NP, Phan HT, Bui TT, Latkin CA, et al. Mobilization for HIV Voluntary Counseling and Testing Services in Vietnam: clients' risk behaviors, attitudes and willingness to pay. AIDS Behav. 2015

52. Mykhalovskiy E, Patten S, Sanders C, Bailey M, Taylor D. Conceptualizing the integration of HIV treatment and prevention: findings from a process evaluation of a community-based, national capacity-building intervention. Int J Public Health. 2009;54:133-41.

53. Brienza RS, Stein MD, Chen M, Gogineni A, Sobota M, Maksad J, et al. Depression among needle exchange program and methadone maintenance clients. J Subst Abuse Treat. 2000;18:331-7.

54. Steward WT, Chandy S, Singh G, Panicker ST, Osmand TA, Heylen E, et al. Depression is not an inevitable outcome of disclosure avoidance: HIV stigma and mental health in a cohort of HIV-infected individuals from Southern India. Psychol Health Med. 2011;16:74-85.

55. Lovejoy TI, Heckman TG. Depression moderates treatment efficacy of an HIV secondary-prevention intervention for HIV-positive late middle-age and older adults. Behav Med. 2014;40:124-33.

\section{Submit your next manuscript to BioMed Central and we will help you at every step:}

- We accept pre-submission inquiries

- Our selector tool helps you to find the most relevant journal

- We provide round the clock customer support

- Convenient online submission

- Thorough peer review

- Inclusion in PubMed and all major indexing services

- Maximum visibility for your research

Submit your manuscript at www.biomedcentral.com/submit 